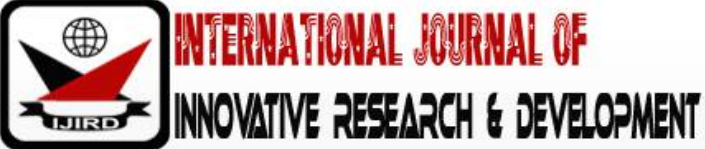

ISSN 2278 - 0211 (Online)

\section{Topographical Map Revision for Sustainable Land Administration and Socioeconomic Development: A Case Study of Ogbomoso Town, Nigeria}

Olufemi Felix Iyiola
Principal Lecturer, Department of Surveying and Geoinformatics,
Federal School of Surveying, Oyo, Nigeria
Ekpo Effiong
Chief Lecturer, Department of Geographic Information System (GIS),
Federal School of Surveying, Oyo, Nigeria
Ayodeji Ajani
Senior Lecturer, Department of Geographic Information System (GIS),
Federal School of Surveying, Oyo, Nigeria
Olusina Aweda
Senior Instructor, Department of Geographic Information System (GIS)
Federal School of Surveying, Oyo, Nigeria
Gbiri Isaac
Senior Instructor, Department of Geographic Information System (GIS),
Federal School of Surveying, Oyo, Nigeria

\begin{abstract}
:
Sustainable land administration system serves as a basis for generating economic development, social coherence and effective land planning. Unavailability of up-to-date topographical maps in African countries is an impediment to the development of an effective land administrative system. Some towns and cities in Nigeria covered by the 1:50,000 topographical maps produced by Federal Surveys some decades ago are out-dated and unsuitable for land planning and socioeconomic development. The study employed geospatial technology to revise the existing 1:50,000 topographical map covering Ogbomoso and its environs to aid land planning and decision making by the government. Methodology adopted for the study involved scanning and digitizing the existing topographical map in ArcGIS, updating the planimetric details with Google earth image while SRTM was used as elevation data. Products generated from the topographical database in ArcGIS included contour map, Digital Elevation Model, stream/ river network, road network, town/ city expansion map. The study recommended that government at all levels should partner with research institutions to update the existing 1:50,000 topographical maps in the country for effective planning and decision making.
\end{abstract}

Keywords: Geospatial technology, digital elevation model, geographical information system, map revision, land administration

\section{Introduction}

Land can be regarded as the most valuable natural resource supporting all human activities and it is from it that all other economic resources are derived. It includes anything on the ground, above the ground, and under the ground, down to the center of the Earth. Two unique characteristics of land distinguish it from other types of property. First, land is immovable, so it cannot be physically transferred from one person to another. Second, land is permanent; it cannot be increased, decreased, or destroyed and this makes land to have lasting recordHanstad (1998).Information about land is a major asset to government and essential for taking well-informed decision. The reform agenda of the Federal Government of Nigeria is a vision for the future which involves the provision of relevant geographic information by the surveying community in form of geographic database of the built and natural environment. The importance of putting appropriate land administration systems in place is for creating economic development, social coherence and to achieve environmental sustainability Opaluwa et al (2014).

Map revision is an important factor in every aspect of land administration since once a map is produced, the graphic image is static and there is a constant need to provide the map with information on changes. High and accelerating rate of the township changes and township area extensions, particular in developing countries, calls for an efficient and fast technique for mapping the urban changes. The availability of satellite imageries has opened a new era and brought 
promising future for production and revision of digital mapsXiong et al (2016). Topographical maps are differentiated from other maps in that they show both the horizontal and vertical positions of the terrain; they portray the shapes and locations of mountains, forests, rivers, lakes, cities, roads, bridges, and many other natural and man-made features. The wide range of information provided by topographical maps makes them extremely useful to both professional and other map users. Topographical maps are used by civil engineers, environmental managers, and urban planners; they are used as basic tools for planning and executing projects, emergency services agencies, and as well by policy and decision makers. They are of prime importance in planning settlements, airports, highways, dams, pipelines, transmission lines, industrial plants, and countless other types of construction. However, revision of topographical maps is a subject which is taking a more central position in surveying, photogrammetry and cartography. This is quite clear when we consider that countries already covered by topographical maps either at small or large scales have to keep their maps up-to-date after the first edition has been published. Furthermore, the society now has a higher requirement for topographical maps that contain the most recent information. It is well known that for planning purposes, technical developments, recreation possibilities, and property registration, recent topographical maps are indispensable.

Socio-economic development is the relationship between economic activity and social life which requires a continuous improvement in the well-being and in the standard of living of the people. It includes access to quality education, better healthcare services, decent housing, safe drinking water, good sanitation and equitable distribution of a nation's wealth. NEPAD(2010).

\section{Problem Definition}

Some existing topographical maps produced by the Federal Surveys some decades ago have not been revised till date. They are out-dated and unsuitable for effective land administration and socio-economic development. Owing to the ongoing development in the country, there is need for topographical map revision of major town and cities in Nigeria. The revised topographical map will model the current changes in the topography of the project area which will serve as a tool for planning, quality and effective decision making and for carrying out sustainable development of the government and other topographical map users

\section{Aim and Objectives of the Study}

The study was intended to revise the existing topographical map on a scale 1:50,000 covering Ogbomosho town in Oyo State, Nigeria. The revised topographical map would serve as a tool to aid planning and decision-making map users and the government. Objectives set for the study included:

- Designing and creating a topographical database for the town

- Scanning and digitizing the existing topographical map

- Updating the map with Google earth image and 1 arc-second of Shuttle Radar Topography Mission (SRTM) data

\section{Study Area}

Ogbomoso is a town in Oyo State, Nigeria and located within latitude $8^{\circ} 00^{\prime} \mathrm{N}$ and $8^{\circ} 15^{\prime} \mathrm{N}$ with longitude between $4^{\circ} 00^{\prime}$ and longitude $4^{\circ} 15^{\prime} \mathrm{E}$. It covers a total land mass of about 63 square kilometres and comprises of Ogbomoso North and South Local Government Areas. The physical and economic growth of the town began in the 19th century when there was an unrest through-out the Yoruba land due to inter-ethnic wars and Fulani Jihad. This brought more than 140 communities to seek refuge in Ogbomosho because of its strong defence. Most of these people took permanent residence in Ogbomosho and by the end of $19^{\text {th }}$ century a continuous built-up compact settlement was evolved from the hamlet, covering an extensive area of land. The rapid growth of the town is also induced by the advent of missionary and establishment of schools. The deportation of Nigerians by Ghanaian Government in 1969 also brought physical and economic growth to Ogbomosho. The establishment of Ladoke Akintola University of Technology in Ogbomosho is said to have induced its phenomenal growth since 1991. The urbanization process that resulted from the development mentioned above led to the demographic change over time. For instance, the population rose from 25,000 in 1885 to more than 166,000 by 1991 (National Population Commission, 1991) and was said to be about 299,535 by 2006 census. Agriculture is the main occupation of the people and its environs which includes Cassava farming and its processing, Yam, Orange, Cashew etc. 


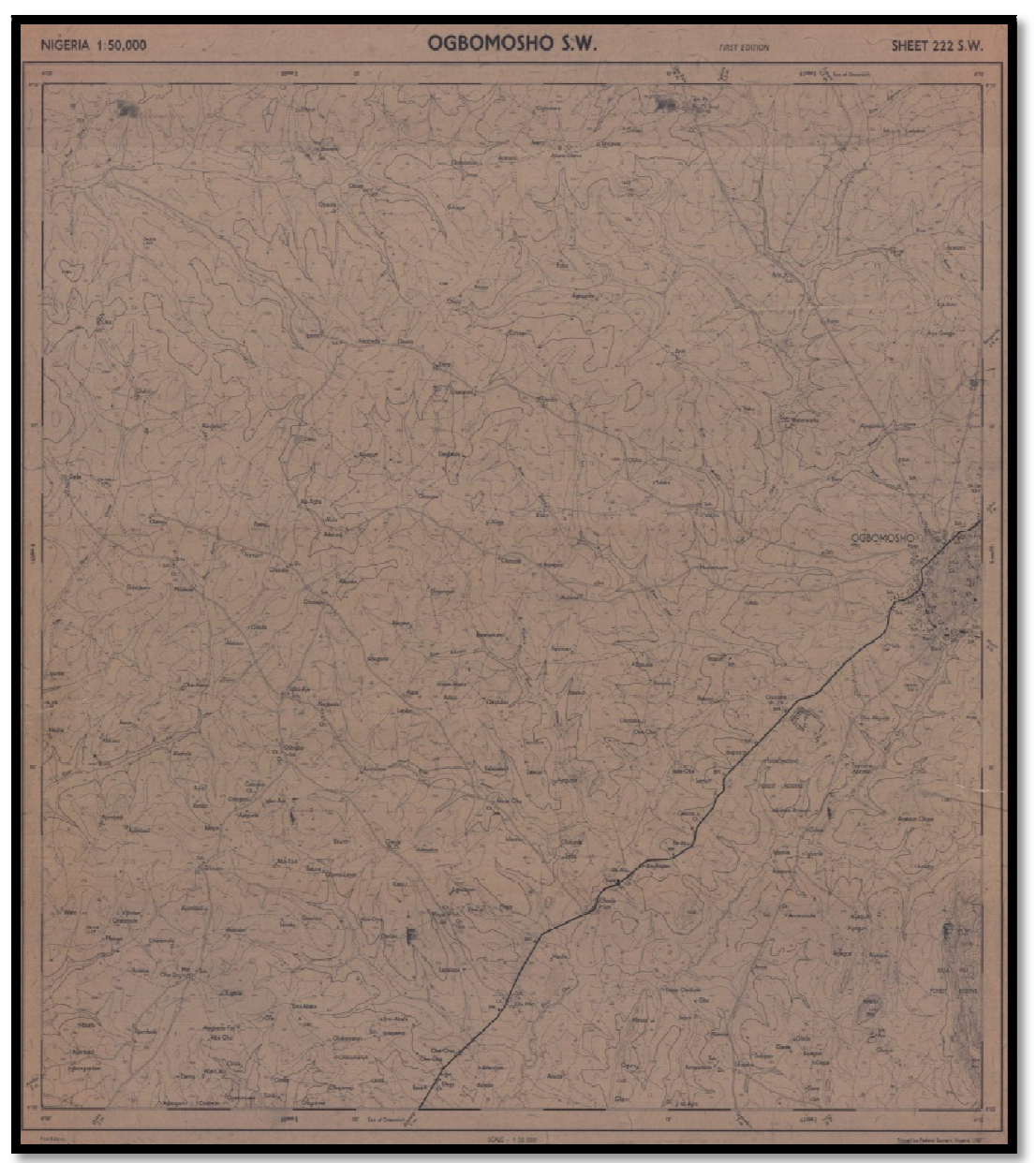

Figure 1: Map of Ogbomoso

\section{Methodology}

\subsection{Database Design}

A topographical database was designed for the town and it involved three stages namely:

- Conceptual design stage: where human conceptualization of reality was adequately represented using vector data model. Spatial entities such as towns, settlements, roads, rivers, religious centres, hospitals, etc. were represented in the database as points, lines and polygons.

- Logical design stage: the representation of the data model was designed to reflect the recording of the data in the computer system. The data structure organized data in a single uniform manner in tables (relations). Each table was identified by a unique table name and was organized in rows (tuples) and columns (attribute).

- Physical design stage: the logical design was represented in the language of the implementation software. For each of the tables created appropriate field, record length, data type was clearly defined and the integrity rules were strictly followed for each table Kufoniyi (1998).

\subsection{Data Sources}

The study made use of the following datasets:

- Topographical map of the town produced by Federal Surveys in 1967 which was scanned and digitized in ArcGIS 10.3. Towns, settlements, rivers, roads were digitized from the map. Projected coordinates in Clarke 1880 ellipsoid (UTM Zone 31N) was used for the map

- Google image for the same area was downloaded and projected to conform with the coordinate system of the existing topographical map already digitized in ArcGIS 10.3. The image was used to update the existing map

- 1 arc-second of Shuttle Radar Topography Mission (SRTM) data was downloaded from earth explorer (https:/ / earthexplorer.usgs.gov/ ). The data was processed in ArcGIS 10.3 using appropriate tools to generate contour lines, slope, aspect, streams and rivers. 


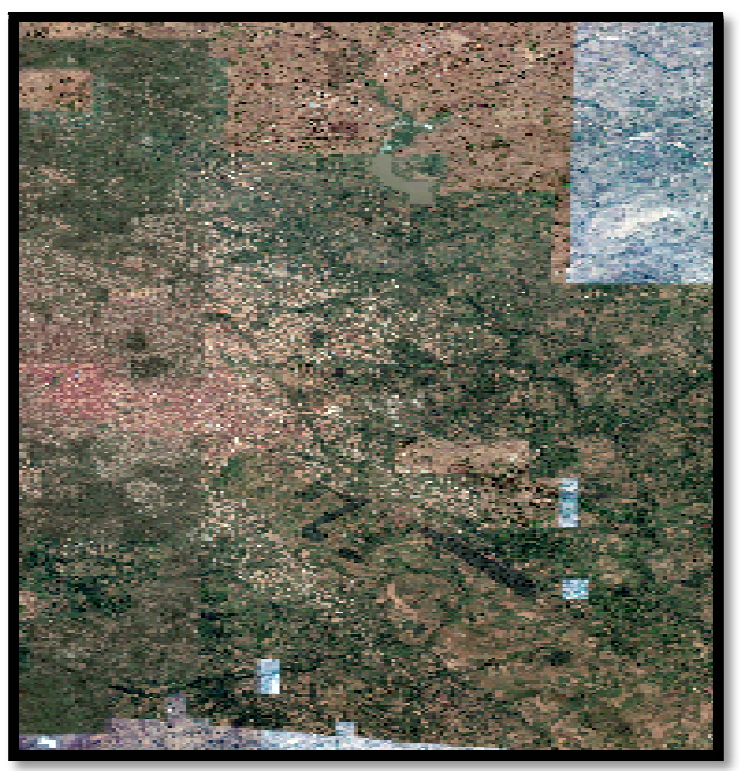

Figure 2: Downloaded Google Earth Image for a Part of Study Area

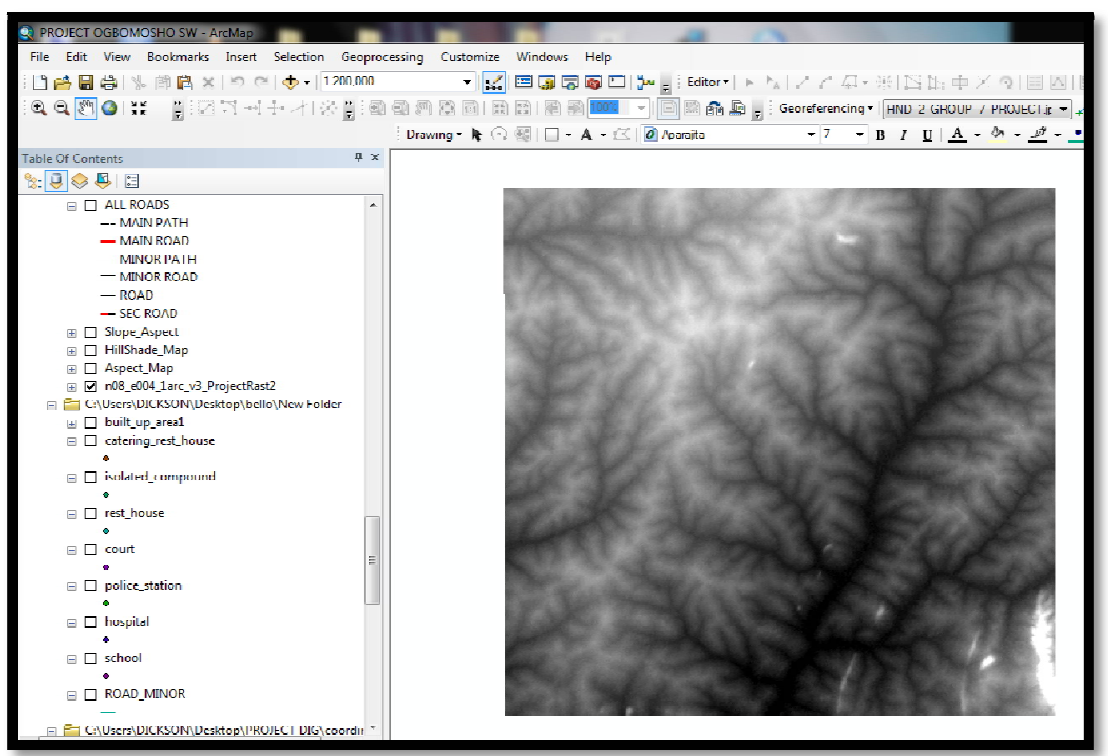

Figure 3: Downloaded 1 Arc-Second of SRTM Data

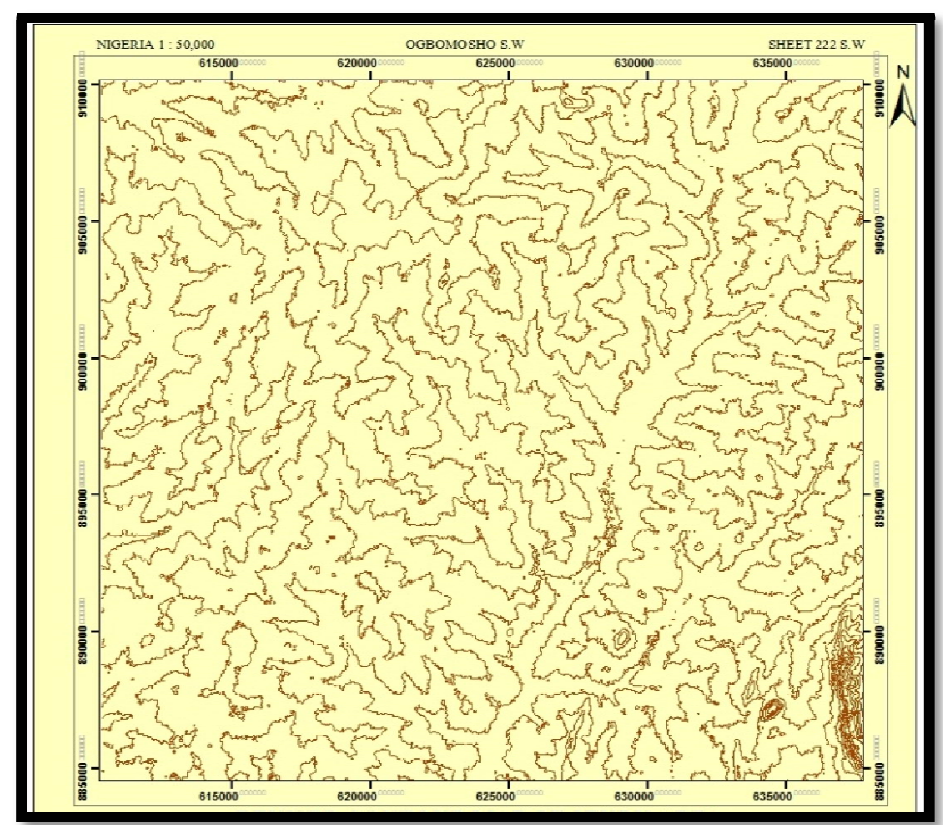

Figure 4: Generated Contour Lines from SRTM 


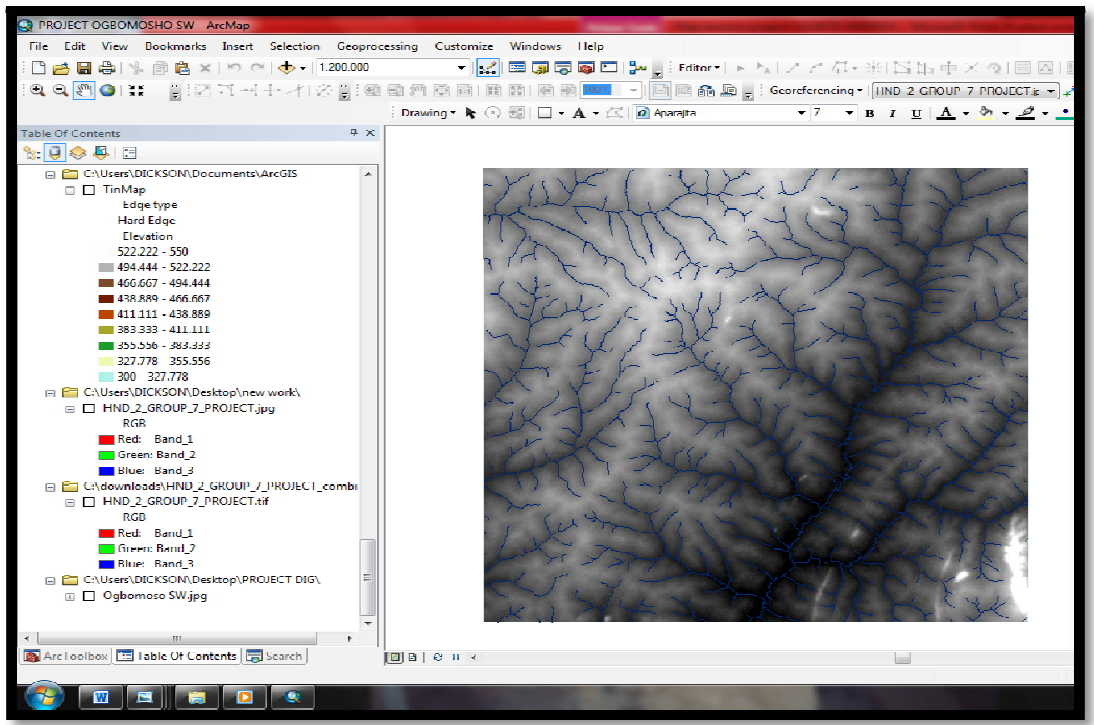

Figure 5: River Network Generated from SRTM and Overlaid on DEM

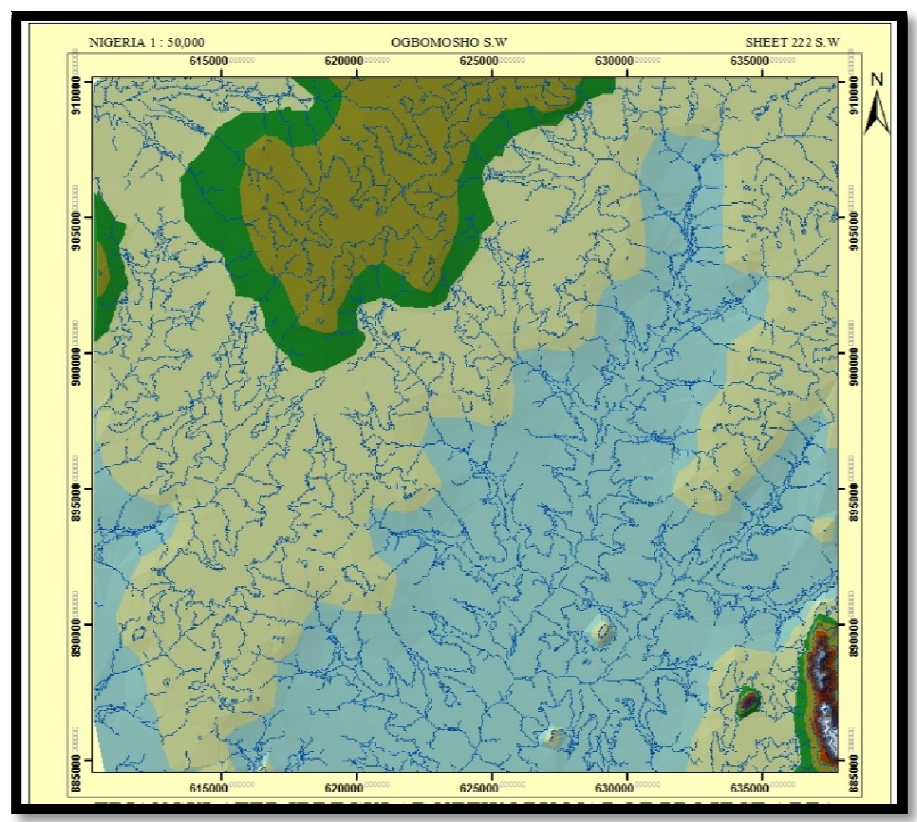

Figure 6: Triangulated Irregular Network (TIN)

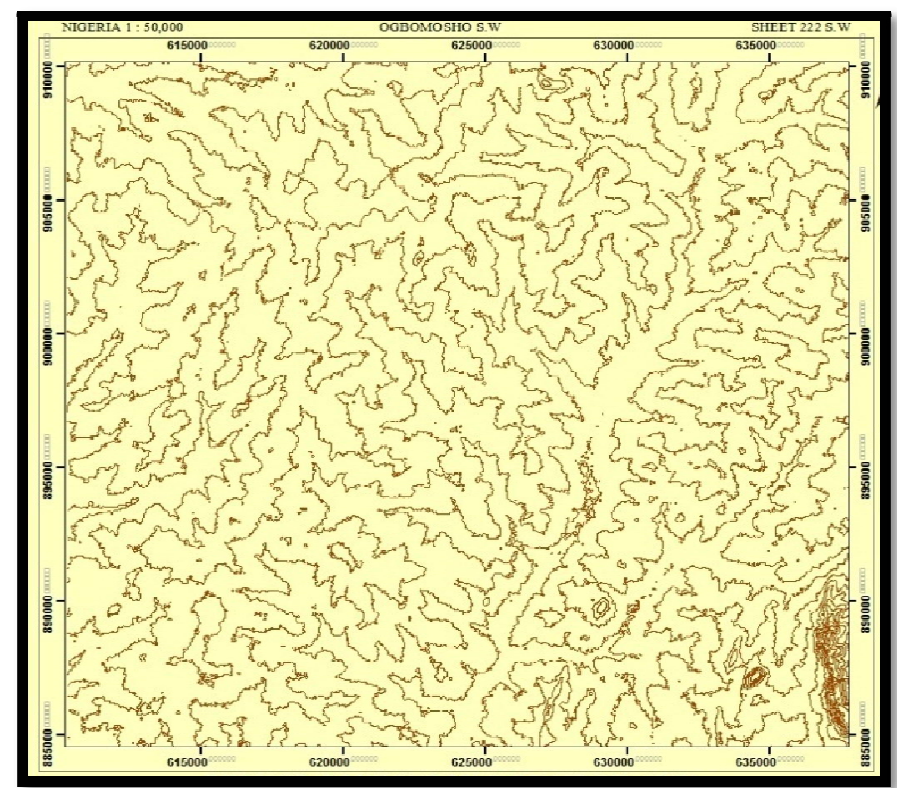

Figure 7: Slope Map 


\section{Land Use and Expansion Analysis}

There has been a vast expansion of some major settlements in the old map and the results how's a high concentration of human activities in major towns. Summary of the settlement expansion is presented in the table 1 below whilethegraphicalportrayaloftheexpansionrateofsettlementfor some major and minor towns is presented in figure 8.

\begin{tabular}{|c|c|c|c|c|}
\hline S/ NO & Settlement & AREA in $m^{2}(2018)$ & AREA in $m^{2}(1967)$ & Difference in $\mathrm{m}^{2}$ \\
\hline 1 & ARAROMI & 60450.13222 & 24941.81568 & 35508.31654 \\
\hline 2 & ALAROPO & 780256.253 & 123916.9758 & 656339.2772 \\
\hline 3 & EGBEJODA & 25152.17738 & 18391.60731 & 6760.57007 \\
\hline 4 & FOKO & 174634.2182 & 13561.8329 & 161072.3853 \\
\hline 5 & OLOJIJI & 53575.41523 & 21355.34154 & 32220.07369 \\
\hline 6 & IPORIN & 326297.9213 & 28584.26744 & 297713.65386 \\
\hline 7 & ALAGBEDE & 50862.717 & 17800.20693 & 33062.51007 \\
\hline 8 & GBANA & 42954.41104 & 15782.09124 & 27172.3198 \\
\hline 9 & SOROTAN & 71497.69823 & 15768.39444 & 55729.30379 \\
\hline 10 & APITI & 265197.2296 & 168040.1421 & 97157.0875 \\
\hline
\end{tabular}

Table 1: Comparison of Settlement Expansion

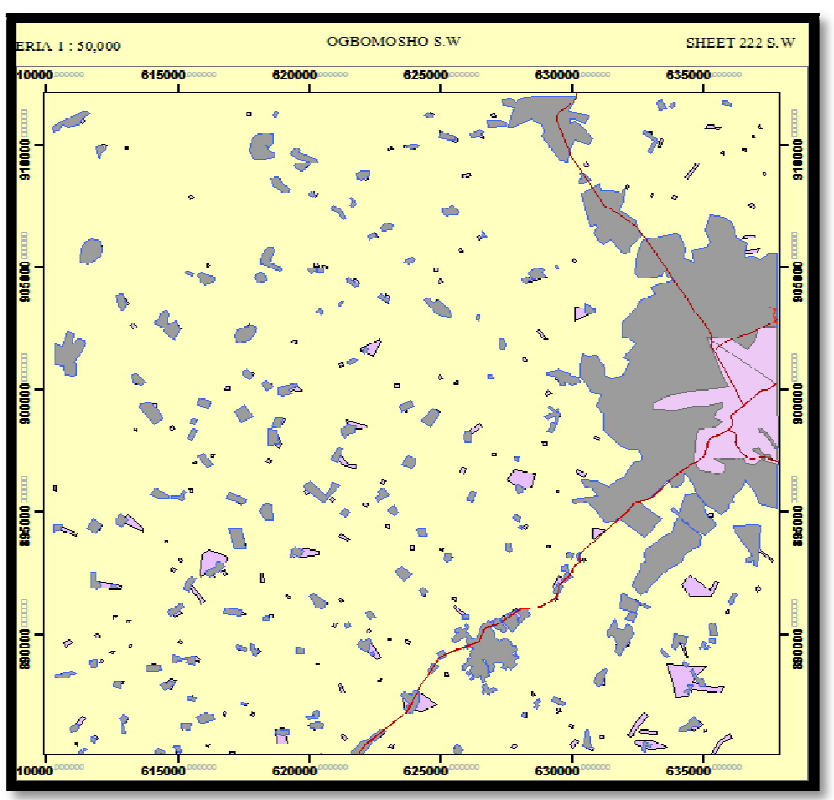

Figure 8: Settlement Expansion

(Grey Areas Represent Expanded Settlements)

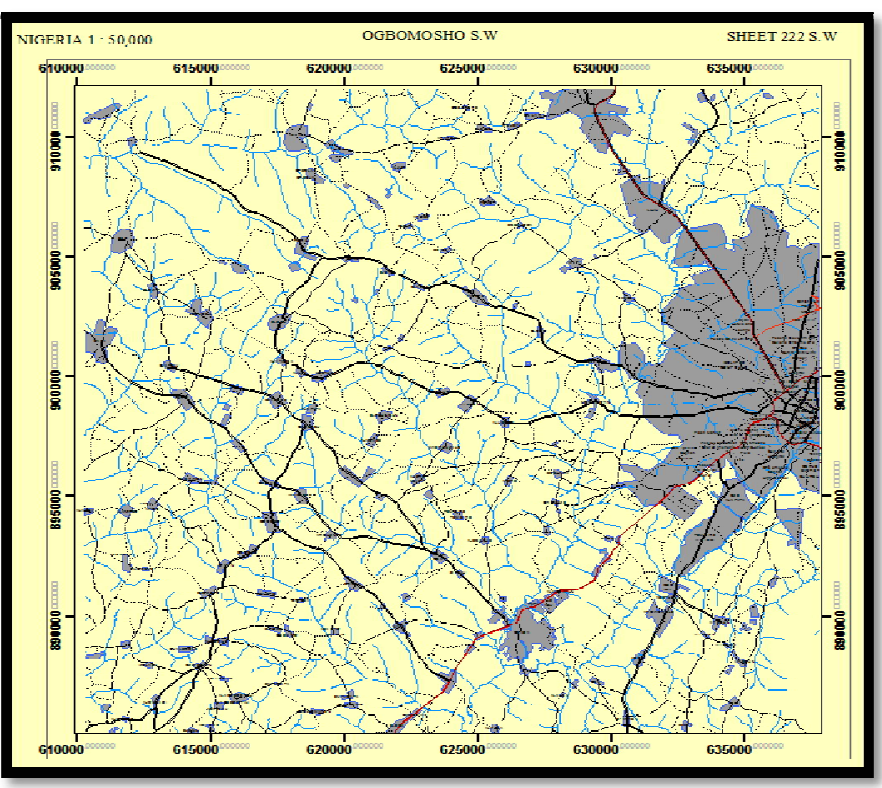

Figure 9: Revised Planimetric Map 


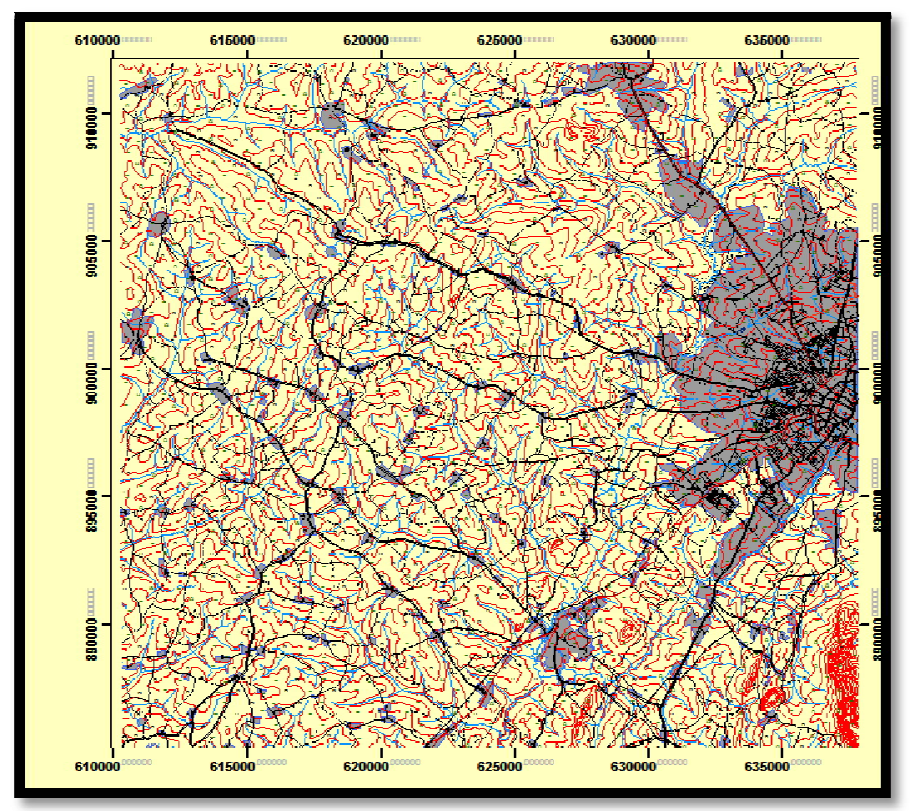

Figure 10: Revised Topographical Map

\section{Discussion of Results}

The study produced a revised topographical map of Ogbomoso. Detection and identification of geographic features such as towns, roads, rivers, vegetation, etc. was easy because of high resolution image used for the exercise. The study and analysis carried out revealed that though there has been development around the study area in terms of roads, expansion of settlements over the years, this development have been slow.

Some portions of land for agricultural use in the old map are now use for residential and commercial purposes while old un-tarred roads have become major roads.

\section{Conclusion}

The existing topographical map of Ogbomoso produced in 1967 has been updated with remote sensing and GIS techniques. The revised map can be used for future planning and development of the town. In conclusion, map makers should gradually embrace the integration of satellite remote sensing, Global Positioning System and Geographic Information System in topographical map revision projects. Remotely sensed data and GIS provide a reliable base for topographical map revision especially when high resolution satellite imagery is used, updating of maps becomes easier and less costly.

\section{Recommendations}

Base on the methodology adopted for this study, the following recommendations are hereby made: -

- The use of remotely sensed data should be adopted for map revision exercises by the relevant government authorities in order to update all existing topographical maps in the country.

- High resolution satellite imageries should be made available at relatively low cost to researchers to aid in mapping and updating existing maps.

- Government at all levels can partner with research institutions to map and update existing topographical maps of the country.

- Adequate provision should be made to include ground thrusting in the process of executing projects of this nature, for its necessity in validating the accuracy of the job.

\section{References}

i. Hanstad T. (1998): Designing Land Administration System for Developing Countries. American University International Law Review 13, no 3: 647-703

ii. Kufoniyi, O. (1998), "Database Design and Creation in Principles and Application of Geographic Information Systems", Edited by C.U. Ezeigbo series in Surveying and Geoinformatics. University of Lagos, pp. 50-57.

iii. National Population Commission (1991): Population Census Data

iv. New Partnership for African's Development (2010): Socio-Economic Development, http:/ / www.aprmzambia.org.zm/ sd.html

v. Xiong, J., Jia, H., Yang, Y., (2016), "Research on Topographic Map Updating with Incremental Mode Base on Remote Sensing Images". Southwest Petroleum University, School of Civil Engineering and Architectural, Chengdu, 610500, P.R, China

vi. Opaluwa Y. D, Adejare Q. A, Samaila-Ija H. A, Onuigbo I, C, Nwose I. A and Idris M. K (2014): Surveying and Mapping in Sustainable Land Administration and Socioeconomic Development in Nigeria: AN Overview. American Journal of Geographic Information System, Vol. 3 No. 2, 2014, pp. 88-97. doi: 10.5923/j.ajgis.20140302.03. 